\title{
Measurement frequency and sampling spatial domains required to characterize turbidity and salinity events in the Guadalquivir estuary (Spain)
}

\author{
E. Contreras and M. J. Polo
}

Fluvial Dynamics and Hydrology Research Group, Instituto Interuniversitario de Investigación del Sistema Tierra en Andalucía (IIISTA), University of Córdoba, Rabanales Campus, Leonardo da Vinci Building, 14071, Córdoba, Spain

Correspondence to: E. Contreras (econtreras@uco.es)

Received: 30 December 2011 - Revised: 19 June 2012 - Accepted: 5 July 2012 - Published: 14 August 2012

\begin{abstract}
Estuaries are complex systems in which long water quality data series are not always available at the proper scale. Data proceeding from several water quality networks, with different measuring frequencies (monthly, weekly and $15 \mathrm{~min}$ ) and different numbers of sampling points, were compared throughout the main channel of the Guadalquivir estuary. Higher frequency of turbidity sampling in the upper estuary is required. In the lower estuary, sampling points help to find out the ETM, and higher frequency sampling of EC is required because of the effect of the tidal and river components. This could be a feedback for the implementation of monitoring networks in estuaries.
\end{abstract}

\section{Introduction}

Water quality monitoring should provide information not only to identify situations corresponding to states of deterioration, but also to permit the study of other aspects, such as their origin, persistence, extreme and base values, etc. All this should be done with a geographical localization and measuring frequency (i.e. at a spatial-time scale) that allow the modelling of inputs from agricultural, urban and industrial areas. They should therefore be designed by addressing the system that is desired to characterize: its morphology, dominating processes and significant scales.

Estuaries are complex aquatic systems in which river and sea dynamics interact, generating some special conditions, which evolve in space and time with different scales (Bramato et al., 2010). On one hand, at a geological scale, the time sequence of large floods and their associated sediments determine the morphology and trend of the estuary. On the other, at a significant rain event scale, floods generate local modifications of the hydrodynamic conditions in the estuary, and, consequently, re-suspension from the bed, local erosion of bed and margins, and deposits of new sediments dragged along by the flood occur throughout the whole estuary. A third aspect is the interaction of river and sea water, which continuously varies throughout the estuary with each tidal cycle, neap and spring tides, and which is drastically altered during brief periods associated with the occurrence of river floods. This determines the magnitude of the spatial-time gradients of salinity and, indirectly, of water density and suspended sediments. Finally, the sediment, nutrient and toxic compound inputs from the basins flowing into the estuary reflect the land uses in those areas and the transformation and transport processes. These inputs result in a regime of state variables, indicators of the water quality and its ecological state, influenced by the meteorological, fluvial, tidal and coastal processes cited. It is therefore necessary to outline the different scales at which each of them happens in order to understand their disparity/matching and the trends in the dynamics of the system. This fact is accentuated when anthropogenic modifications come into play, which is the case of the intensive regulation per reservoir in the drainage area, whose discharges can vary depending on the inputs, rainfall, demands and other factors. For those reasons, estuaries are a clear example of the importance of designing measurements and sampling oriented towards capturing all their significant spatial-time variability when finding out how they work, what their state is and how they evolve. 
Salinity and turbidity are two key state variables for understanding the dynamics of an estuary. Their spatial-time variability is related to the significant scales of the governing processes and to the geometry of the estuary. In the time context, the values of the two state variables evolve during the tidal cycle and respond to the sequence of live and neap tides and annual cycles and, likewise, occasionally to fluvial discharges (Hardisty, 2007). During the flood tide (rise in sea level during the tidal cycle), the estuary tends to become filled upstream with sediments brought in from the sea or from the river. At the same time, the depth of the shallow waters and the increase in friction affect the volume of the tidal prism and response, so that the currents diminish. However, during the ebb tide (lowering of the sea level during the tidal cycle), the estuary tends to empty the sediments, increasing the depth of the water and altering its response towards the flood dominance (Dyer, 1997). Analogously, in the spatial context, those values vary (in addition to with the depth) along and across the estuary. Thus, in an estuary, one or several areas where estuarine turbidity maxima (ETM) are produced can be localized, and they move up or down them cyclically. These maximum turbidity points signify the areas where the entry of the tidal flow is significantly reduced, and the sediments dragged along by it and those transported by the freshwater flow meet up, and remain in suspension in areas of very low or null net velocity, slowly decanting. They are therefore usually located in the medium-low stretches of the estuary, depending on its length and on the tidal dynamics. Also, since salinity favours flocculation of the sediments, the latter tend to decant with a greater ease in the areas dominated by the tides; in partly or well mixed estuaries, the area with the highest turbidity (ETM) is reached in low salinity zones. In any section inside the estuary, salinity slightly varies with its depth and breadth, although in certain phases of the tidal cycle (these are more marked close to the river mouth), longitudinal saline stretches can be produced, and variations in the longitudinal and vertical distribution, which mainly depend on the hydraulic regime of the river, can be noted. Increments in the river flow usually increase its stratification and likewise cause the suppression of the turbulent mixture due to the density stratification downstream of the salt wedge, which amplifies the capture efficiency for a range of settling velocities of the fastest particles (Geyer et al., 1998). According to Sanford (2001), particle settling velocity depends on the season in which large events occur, because the fate of delivered sediments may be different.

All this demonstrates the complexity of estuary dynamics and the need for the availability of specifically designed monitoring networks using the knowledge of those processes. But this is not always so; the monitoring networks are usually designed with static criteria regarding the frequency of sampling. There is not a sufficient number of stations to measure all the parameters necessary, and, when they exist, they have been recently set up so that the series available do not have a sufficient extension to characterize the time variability significantly. This has a greater influence in the case of Mediterranean areas. Also, sometimes, information from diverse sources is available and its assimilation is not direct. The European Water Framework Directive (WFD) specifically establishes the requirements and limiting conditions for the achievement/maintenance of water quality in semienclosed seas and estuaries (transitional waters), where the interaction between fluvial and tidal dynamics leads to great ecological diversity. The directive establishes a minimum frequency of 1 month to monitor priority substances in transitional waters, and 3 months for the remaining of the physicochemical indicators. In Spain, this control program is performed by fixed monitoring stations with monthly sampling, independently of the tidal regime.

The Guadalquivir estuary is located in southern Spain, facing the Atlantic Ocean. It is largely regulated by the reservoir network upstream along its contributing basin $\left(47900 \mathrm{~km}^{2}\right)$, with a storage capacity of up to $8900 \mathrm{hm}^{3}$ (Contreras and Polo, 2010). Closed in upstream by Alcalá del Río dam (Fig. 1), it receives fluvial discharges associated with significant rainfall events during autumn and winter, and irrigation demands (both water quantity and salinity control) in the estuary area during spring and summer. Episodic events of persistent turbidity and/or salinity occur, and, from 2007 to 2011, a specific monitoring network consisting of 15 control points instrumented with sensors for weather variables, water flow and water quality was installed along its main channel in a scientific research framework. The dataset provided characterization of both water flow and water quality regimes with a high frequency (Navarro et al., 2011). Its analyses provided a deep insight into the relevant scales for each process in the estuary, and led to the modelling of the tidal dynamics (Díez-Minguito et al., 2011) and other significant components (work under revision at the moment).

For medium- and long-term modelling of water quality in the estuary, long series are needed. However, as described above, the available monitoring networks exhibit great differences in series duration and measurement frequency, and constitute the only current data source, since the instrumentation used in Navarro et al. (2011) was dismantled after the project. Merging both data sources poses a constraint due to their different spatial and temporal scales.

This work shows the effects of scale when surface water quality data proceeding from different networks, with different measuring frequencies and a different number of sampling points (different spatial-time scale), are assimilated. It identifies the main difficulties and needs existing in the characterization of the dynamics of the variables that define the water quality. For this purpose, the Guadalquivir estuary has been focused on because of its representativeness of the situation described and its importance as a water mass at many levels. Two parameters were selected to characterize water quality: turbidity, a key parameter, which is a good tracer of its hydrodynamics; and salinity, a representative parameter of the hydrologic conditions (marine intrusion, 


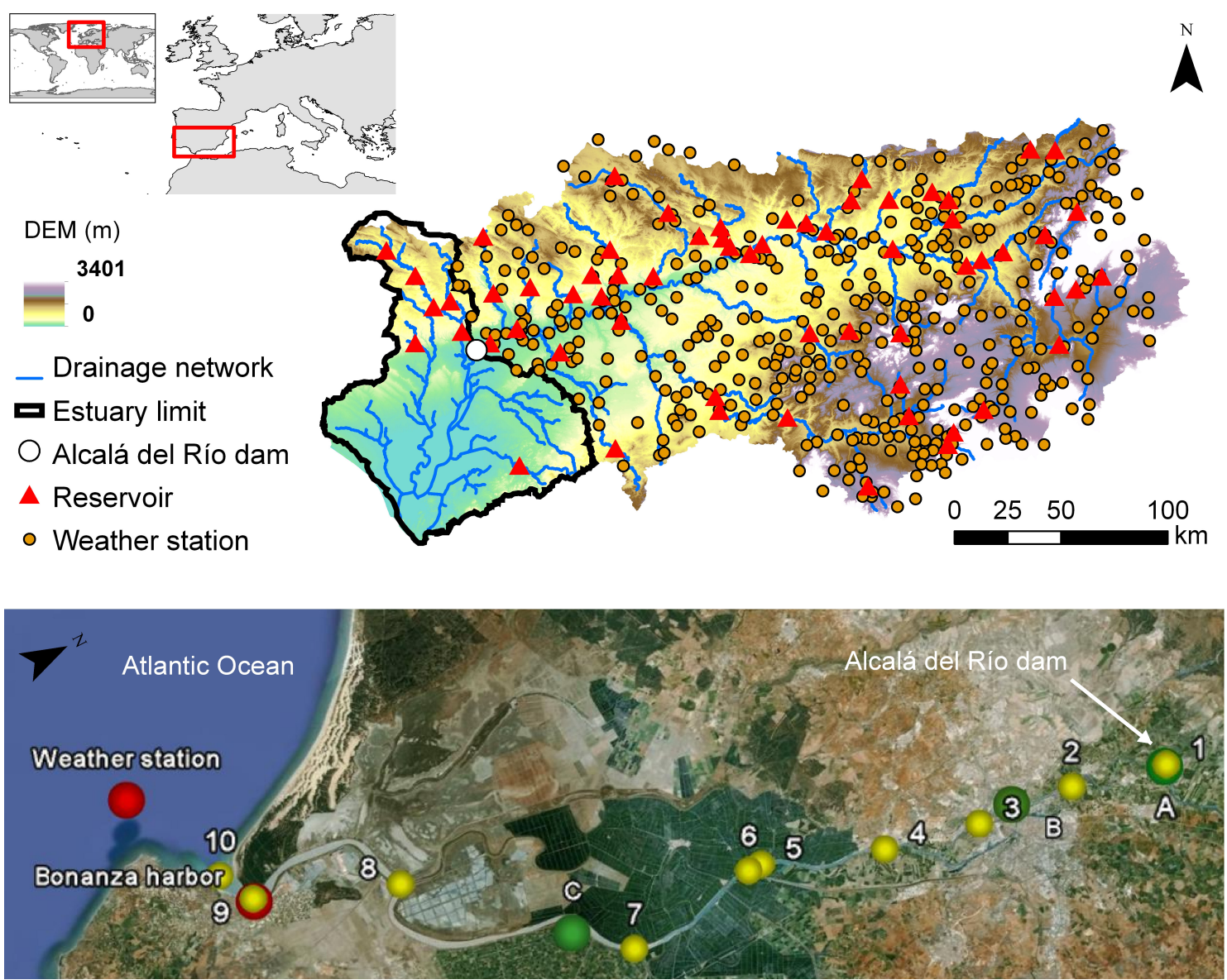

Fig. 1. Location of the Guadalquivir basin and estuary, reservoirs, Alcalá del Río dam and weather stations upstream, and water quality, fluvial and maritime stations in the estuary.

riverine discharges, seasons) (Etcheber et al., 2011). Turbidity and salinity in the Guadalquivir estuary need to be studied, given the scant literature about these water quality variables in this particular area (Bustamante et al., 2009; González-Ortegón et al., 2010) and in light of the recent work carried out (Navarro et al., 2011; Díez-Minguito et al., 2011). The results of this work stress the importance of designing high frequency monitoring networks in these kinds of estuaries.

\section{Data and methods}

\subsection{Description of the study area}

The Guadalquivir estuary is situated in southwestern Spain, occupying an area of approximately $9500 \mathrm{~km}^{2}$ of the $57400 \mathrm{~km}^{2}$ making up the whole of the actual hydrographic basin of the Guadalquivir River, and it is affected by the general dynamics of the Gulf of Cadiz waters and by very ample tides. Although it receives a marked Atlantic influence, the Mediterranean climate in which it is framed means that, in general, most of the rainfall is concentrated in the winter months, with peak values from November to March. The mean annual rainfall for the period from 1945 to 2010 was $530 \mathrm{~mm}$.

The contribution of fresh water to the estuary is subject to an intense regulation from the Alcalá del Río dam $(110 \mathrm{~km}$ from the river mouth), which blocks the tidal wave upstream. Also, there are fluvial inputs, both regulated by reservoirs and in a natural regime, from the basins flowing into the system downstream from the dam. However, their amount is several orders of magnitude lower with respect to the inputs from the dam (Fig. 1). These water flows ensure a more or less continuous amount of water with a mean value of $10 \mathrm{~m}^{3} \mathrm{~s}^{-1}$ order, with increments associated with the occurrence of rainfall in discharge pulses lasting one or several days, which normally reach one more order of magnitude $\left(100 \mathrm{~m}^{3} \mathrm{~s}^{-1}\right)$, and with extreme values of higher orders $\left(1000 \mathrm{~m}^{3} \mathrm{~s}^{-1}\right)$. Lower discharges are also produced at irrigation times to control the salt intrusion for agricultural purposes $\left(100 \mathrm{~m}^{3} \mathrm{~s}^{-1}\right)$. The input of salt water is fundamentally associated with the tidal dynamics of an essentially semi-diurnal nature, varying its 
amplitude in cycles of live and neap tides of approximately 14.5 days. Twice a year, coinciding with the equinoxes, the highest live and neap tides occur. It is a mesotidal estuary with a breadth varying approximately between $800 \mathrm{~m}$ and $200 \mathrm{~m}$, and an average depth of $7.1 \mathrm{~m}$. Depth and velocity at each point of the estuary depend on the behaviour of the tidal wave, in particular on its components M2, S2 and their corresponding harmonics, which provide the asymmetry of the tide and of the velocity field. The spatial evolution of the wave celerity in each stretch of the estuary is indicative of the equilibrium or disequilibrium between the asymmetry and the bottom friction. Under normal flooding conditions, the high average velocity associated with the tidal wave, around $1 \mathrm{~m} \mathrm{~s}^{-1}$, with respect to the small flow of fresh water, characterizes the estuary, according to the classification of Pritchard (1952) as being vertically homogeneous or well mixed, this characteristic being partly altered during periods of heavy floods (Álvarez et al., 2001). Thus, the regime of impulse discharges, together with the quasi-one-dimensional morphology and a prominent reflection of the tidal wave in the dam, directly affects substance dynamics and transport.

According to Díez-Minguito et al. (2011), at tidallyaveraged scale there are two ETMs. The first, downstream, is mainly due to the increment in the re-suspension capacity because of a significant transverse circulation in areas with small curvature radii. The second, upstream of the estuary, could even reach the dam itself and is associated with the presence of the null point of saline intrusion and with the stationary nature of the wave propagation in this stretch of the estuary. Throughout the year, the ETMs are displaced up or down from the main channel, depending on the tidal surge and on the magnitude of the fluvial discharges, whose synchronization with respect to the cycle of neap tides causes a great interannual variation in the sediment flow.

\subsection{Water quality networks existing in the estuary}

The current monitoring networks established by the institution in charge of the integrated basin-based water management of the Guadalquivir basin (Guadalquivir Basin Confederation) in order to control the surface continental waters (rivers, reservoirs, lakes and wetlands) are two: Integrated Network of Water Quality (ICA), which is based on monthly periodic sampling; and the automatic sampling (with 15 min frequency) stations of the Automatic Information System on Water Quality (SAICA). There is also a boat network focussed on the turbidity and salinity control, established by the Andalusian Regional Government (JA), which takes measurements at a weekly scale. These networks will be defined below.

\subsubsection{Monthly network}

The ICA network is organized in fixed monitoring stations in which, from January 1981 to November 2008, periodic controls were made approximately monthly on samples of water analyzed in the laboratory, with physicochemical and microbiological parameters. These instantaneous samples are carried out on a specific day of the month, which is different from one month to another. This network was defined to complete the objectives of the WFD in both physical and chemical aspects, but the sampling frequency continued being monthly. Measurement of suspended sediments concentration (SSC) $\left(\mathrm{mg} \mathrm{L}^{-1}\right)$ and electrical conductivity (EC) $\left(\mu \mathrm{S} \mathrm{cm}^{-1}\right)$, as an indicator of salinity, was carried out. There are 3 stations located at the main channel of the estuary: stations $\mathrm{A}, \mathrm{B}$ and $\mathrm{C}$, upstream, $18 \mathrm{~km}$, and $65 \mathrm{~km}$ downstream from the Alcalá del Río dam, respectively. These stations are shown in Fig. 1.

\subsubsection{Weekly network}

Furthermore, from April 2008 to May 2011, a network of boats (JA network) takes in situ measurements of quality parameters with a weekly frequency. This network measures SSC $\left(\mathrm{mg} \mathrm{L}^{-1}\right)$, turbidity in Nephelometric Turbidity Units (NTU), understood as being the lack of transparency of the water due to the presence of particles in suspension, and $E C\left(\mu \mathrm{S} \mathrm{cm}^{-1}\right)$, at ten stations located along the main channel of the estuary, downstream from the Alcalá del Río dam to the river mouth (1-10 stations in Fig. 1).

\subsubsection{Automatic network}

Also, the SAICA transmits continuous analytical data in real time with frequency intervals of $15 \mathrm{~min}$, available from October 2004 to September 2010. The system analyzes turbidity (NTU) and $E C\left(\mu \mathrm{S} \mathrm{cm}^{-1}\right)$. Only one station is situated in the main channel, upstream of the Alcalá del Río dam (station A in Fig. 1).

\subsection{Selection of control points}

In order to localize and assess the inputs to the estuary, the basin upstream of the estuary was evaluated, its drainage point being the Alcalá del Río dam (station A), where there are ICA and SAICA stations. Thus, this control point represents a source of specific inputs, which aggregates all of them, both point and diffuse, generated upstream. The contributions from the dam are $80 \%$ of the inputs to the estuary, so that this allowed the characterization of the influence of discharge pulses on the water quality throughout the main channel of the estuary. Likewise, this influence was evaluated in stations situated along the main channel of the estuary with different spatial scales in the ICA and JA networks, since in the first case there were two stations (B and C) and in the second ten stations (1-10) (Fig. 1). 


\subsection{Other data sources used: fluvial, maritime and land networks}

Maritime and fluvial information on tide and river flow was used, which helped to understand the origin of turbidity episodes and their maintenance in the time. This information was compiled by taking (1) a fluvial station with daily water discharge data from the Alcalá del Río dam, provided by the Andalusian Regional Government, and (2) two maritime stations situated out to sea, with wind data recorded every $10 \mathrm{~min}$ at a height of $10 \mathrm{~m}$ ( 3 hourly averaged), and hourly tidal height in Bonanza harbour, both data provided by the Spanish Ports Authority. Moreover (3), 490 land weather stations in the basin upstream the dam, provided by the Andalusian Regional Government, were used to calculate the mean daily rainfall in the contributing area to the dam, taking into account the influence of its topography (Herrero et al., 2007). This information is shown in Fig. 1.

\subsection{Analysis of the information available}

To analyse the effects of the spatial time scale of the networks available in the area and their possible data assimilation, the following steps were taken.

\subsubsection{Temporal evolution of the water quality at the control points}

Due to the characteristics of every dataset (frequency, time series extent, data source, file format), a huge amount of work deals with data preprocessing, and filtering for automatically detecting outliers and errors was carried out. An analysis of the temporal evolution and extreme values for each variable was carried out. This task allowed defining the estuary stretch with a similar range of turbidity and salinity values.

\subsubsection{Comparison of measurements, at their individual scales, of different networks at the same control point}

Conversion from turbidity to SSC data was required in order to compare SAICA and ICA data, using a linear regression conversion found in JA data, which measures both variables. Moreover, to facilitate plotting, a software tool was developed within Matlab with a user interface (Bramato et al., 2010) that allowed the plotting of multiple variables collected from different stations.

\subsubsection{Selection of turbidity events and analysis of their origin and persistence}

A turbidity event with weekly data available was selected, and the meteorological, fluvial and coastal context of the study period was considered, with the aim of determining the forcing processes of each state in the different stretches of the estuary: higher, middle and lower.

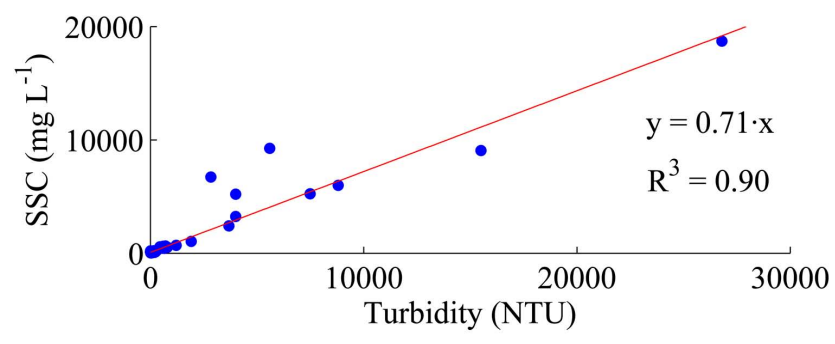

Fig. 2. Linear regression relation between SSC and turbidity in 1 station, from available data of the JA network.

\section{Results}

\subsection{Influence of the spatial-time scale on SSC data throughout the estuary}

Relation between turbidity and SSC was different in each estuary stretch, since slopes of light attenuation vs. particle mass concentration regressions systematically vary with the size distributions of the particles (Baker and Lavelle, 1984; Sanford et al., 2001), so different particle populations were found in the estuary. In this case, the relation found in station 1 (Fig. 2) was used, according to $\mathrm{SSC}=$ Turbidity 0.71 , with an $R^{2}$ of 0.9 .

Figure 3 presents SSC data with 15 -min, weekly and monthly frequency, from SAICA (station A) JA (stations 110 ), and ICA (stations A-C) networks, respectively, during the period October 2004-July 2010 (study period in which data of the three networks are available), according to the situation in the upper, middle and lower estuary. Upstream of the Alcalá del Río dam (station A), a different maximum turbidity value was found for each scale: at a monthly scale, SSC maximum value was $100 \mathrm{mg} \mathrm{L}^{-1}$, while at a 15 -min scale, a value close to $400 \mathrm{mg} \mathrm{L}^{-1}$ was often found, and even higher values in 2009 and $2010\left(4000-8000 \mathrm{mg} \mathrm{L}^{-1}\right)$. The same happened in the upper estuary, but in this case monthly data (station B) showed higher SSC values than upstream the dam, around $600 \mathrm{mg} \mathrm{L}^{-1}$. However, frequently higher SSC values found in the lower estuary (stations $4,5,6,7, \mathrm{C}, 8$, 9 and 10) suggest that turbidity events in this stretch could be captured at a monthly scale (up to $800 \mathrm{mg} \mathrm{L}^{-1}$ was found in station C), although their magnitude would depend on the tidal state when the data collection took place because of the effect of the tide on the SSC variability (Fig. 3).

Other studies took SSC measurements in the Guadalquivir estuary with a lower frequency (two sampling campaigns, during the wet and dry season, in 2001-2003 (Mendiguchía al., 2007) and in 2007-2008 (López-López et al., 2011)), and they do not detect values higher than $200 \mathrm{mg} \mathrm{L}^{-1}$ in the upper estuary. This suggests the importance of controlling the sediment input loads to the estuary by high-frequency sampling. 

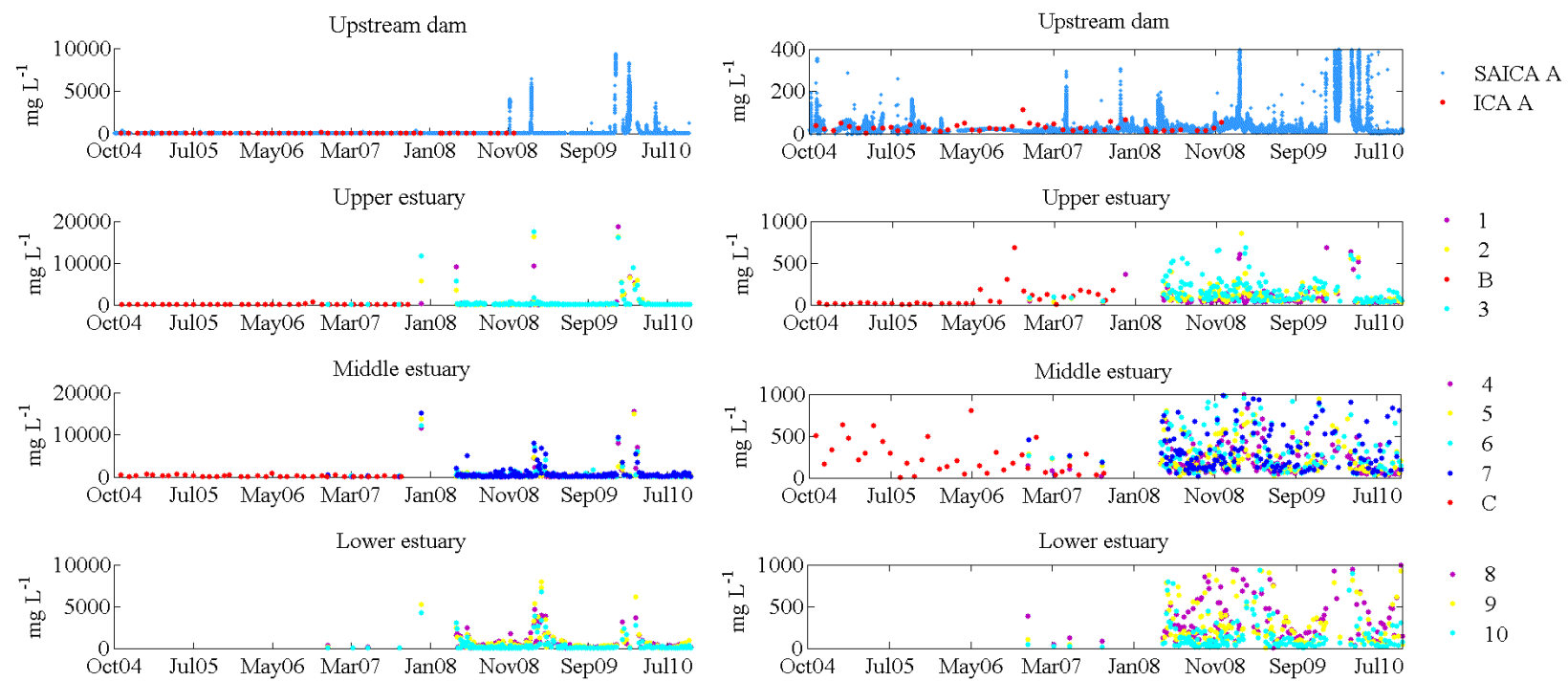

Fig. 3. SSC in ICA, JA and SAICA stations throughout the estuary, period October 2004-July 2010 (left), and showing values below $400 \mathrm{mg} \mathrm{L}^{-1}$ upstream of the dam and below $1000 \mathrm{mg} \mathrm{L}^{-1}$ in the estuary (right).

\subsection{Influence of the spatial-time scale on conductivity data throughout the estuary}

Figure 4 shows 15 -min, weekly and monthly frequency data during the period October 2004-July 2010, according to the situation in the upper, middle and lower estuary. Upstream of the Alcalá del Río dam (station A), the maximum EC value of monthly data $\left(2500 \mu \mathrm{S} \mathrm{cm}^{-1}\right)$ was similar to that at a 15 -min scale $\left(2802 \mu \mathrm{S} \mathrm{cm}^{-1}\right)$. Likewise, up to $20 \mathrm{~km}$ downstream from the dam, monthly (station B) and weekly (stations 1, 2 and 3) data did not show large differences, with peak values of around $1500 \mu \mathrm{S} \mathrm{cm}^{-1}$. However, from $20 \mathrm{~km}$ downstream from the dam to the river mouth, large differences were found between monthly (station C) and weekly (stations 4-7) data, with peak values of around $9000 \mu \mathrm{S} \mathrm{cm}^{-1}$ and $20000 \mu \mathrm{S} \mathrm{cm}^{-1}$, respectively (note that stations 4-7 are upstream from station $\mathrm{C}$, so the latter should show a higher EC). This could be due to the EC values in this area being severely affected by the tidal wave that causes greater differences in its salinity. This implies the need to control the EC variable at a higher frequency in the tide dominance area.

\subsection{Tidal variability in turbidity and salinity events}

The meteorological, fluvial and coastal context was analyzed during the turbidity event that occurred in February 2009, in order to establish a causative mechanism for the tide-driven variability. From top to bottom, Fig. 5 presents average daily discharge from the Alcalá del Río dam and average daily rainfall in its contributing area, weekly SSC and EC measurements along the estuary, tidal variation and mean wind direction in the river mouth, during January-April 2009. It was observed that, in the upper estuary (stations 1-3), the sediments dragged by the river with mean discharges of 100$500 \mathrm{~m}^{3} \mathrm{~s}^{-1}$ carried on (only on one occasion was a high concentration of close to $17000 \mathrm{mg} \mathrm{L}^{-1}$ recorded) due, on one hand, to the greater transport of the fluvial component in this stretch and, on the other, to the lesser efficiency of sediment capture. However, the opposite occurred further downstream, where increments in the river flow usually increased the stratification of the density and the suppression of the turbulent mixture downstream of the salt wedge, resulting in a greater retention of particles, united to the tidal surge and re-suspension of sediments. These processes were aggravated by the spring tides, which contributed to generating a state of permanent turbidity $\left(500-800 \mathrm{mg} \mathrm{L}^{-1}\right)$ in the middle and lower estuary (stations 4-10). This was amplified in spring tides (2000-8000 $\mathrm{m} \mathrm{L}^{-1}$ ), displacing the ETM upstream and downstream (in Fig. 5, the ETM is situated in stations 6-7, 7-8, and 9, consecutively) when sediments were exported to the river mouth. Near the river mouth, the velocity reduction near the bed, caused by the increase in the transversal river section width and the existence of moderate winds rotating $360^{\circ}$ from north to west, increased the mixing of estuarine turbid water with cleaner ocean water, and contributed to reducing the value of the global local turbidity.

\section{Discussion}

Weekly scale data are useful for characterizing the turbidity and salinity of the estuary, since they are capable of capturing the peak values and diminutions of both variables, although sometimes they do not completely reflect the intensity of the episodes, as the 15-min scale data do. However, at a monthly scale, the record of the extreme values is very often lost. This 


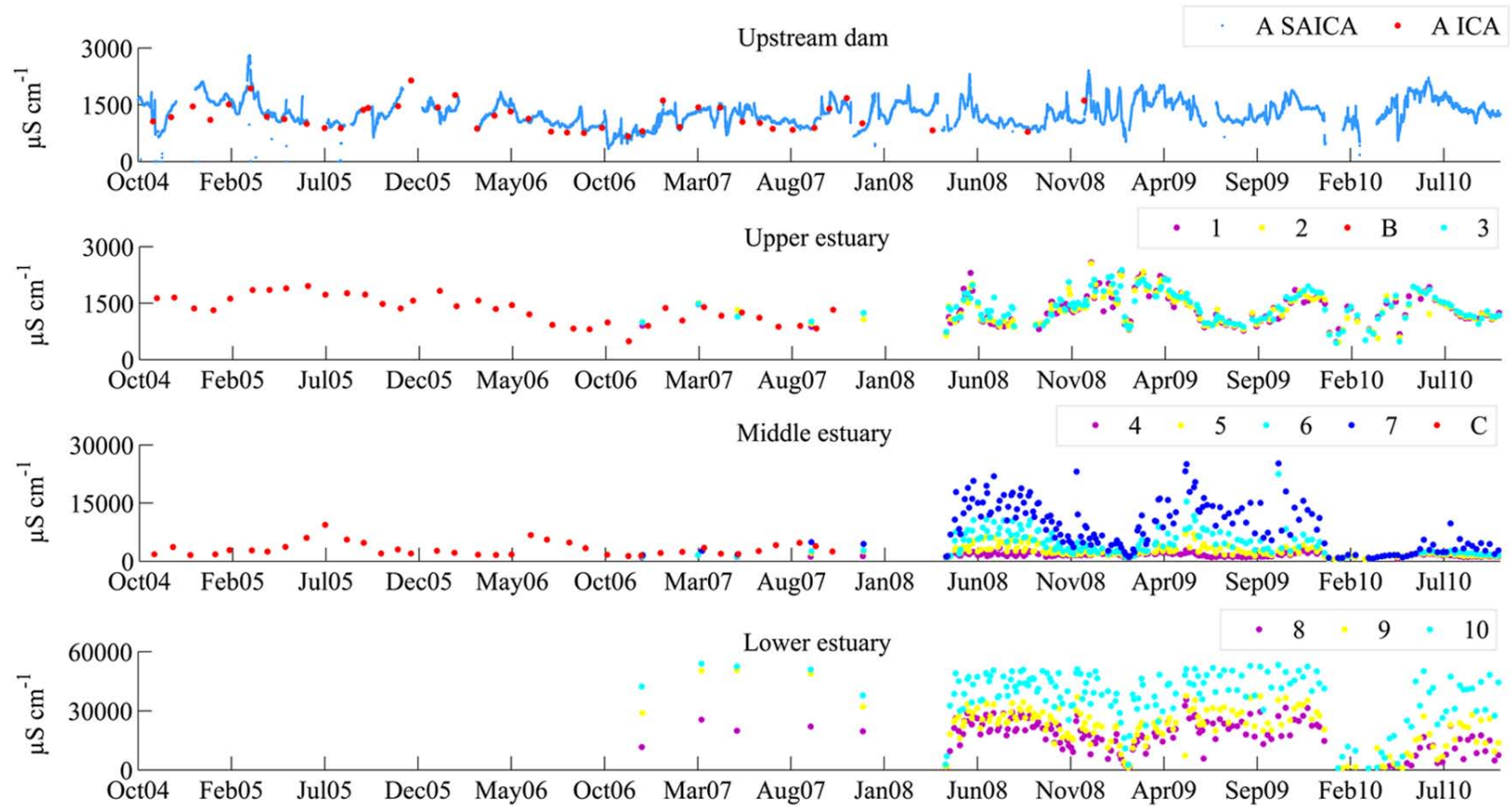

Fig. 4. EC in ICA, JA and SAICA stations throughout the estuary, period October 2004-July 2010.

loss of information differs with regard to the study variable, depending on its spatial-time variability. Regarding turbidity, as this advances towards the head cut of the estuary, carrying out high frequency sampling becomes more important, in order to control the sediment input loads to the estuary. At least a weekly time scale is required since the extreme episodes of turbidity in the upper and middle estuary were not recorded at a monthly scale. However, in the lower estuary, the resuspension, tidal surge and resulting permanence of the turbidity permit the extreme episodes to be captured with relative ease at a monthly scale. Moreover, a higher number of sampling points is important in order to find out the ETM, because this varies between the middle and lower estuary, according to the river discharge pulses and tidal jump. In the case of the EC, a lower sampling frequency can be used in the upper estuary, but a higher time scale is required in the lower estuary, where the salinity is subject to sudden changes due to a lack of river flow or, on the contrary, to floods.

According to available data, turbidity events upstream of the dam and in the upper estuary usually took place over 3-4 days (in response to heavy rainfall and fresh water input from the basin upstream of the dam), so that the maximum values recorded at monthly and $15 \mathrm{~min}$ scales were very different. Likewise, in comparing monthly and weekly data (Fig. 3), the possibility of capturing high turbidity with the latter increased significantly, although there was a $50 \%$ non-detection probability, if the sediment load input had occurred within 3-4 days of the week in which a measurement had did not taken place. However, in the lower estuary, even when data collection was carried out a few days after the turbidity event, its persistence over time in this area allowed it to be detected with monthly measurements. This is because the restoration of the ETM after river flooding pulses to its normal magnitude requires several months (Grabemann et al., 1995).

The existence of an adequate spatial scale also facilitates the analysis of the forcing processes of turbidity and delimits the stretches of the estuary in which the latter occur, which becomes impossible if only a couple of sampling points are available throughout the mean channel.

The results of this work suggest that the minimum frequency that WFD establishes may not be enough to take into account the variability in terms of turbidity and salinity, resulting from both natural and anthropogenic conditions in the Mediterranean estuaries, where rainfall variability, heterogeneous topography, land uses and reservoirs interact in these complex aquatic systems. So, particular care would be required in such important water bodies, not only for scientific purposes but also for regular monitoring/correcting actions in water resource planning, given the enormous biodiversity and socio-economic activity of these ecosystems. As has been stated in the Introduction section, during four years, an automatic high-frequency measurement network to diagnose and predict the consequences of human activities on the Guadalquivir estuary (Bramato et al., 2010; Navarro et al., 2011) has been operated. However, this kind of network requires a great amount of instrumentation and personnel, not only for its installation but also for its maintenance, whose cost is not always possible to assume. For that reason, standard networks are the source data usually available, 


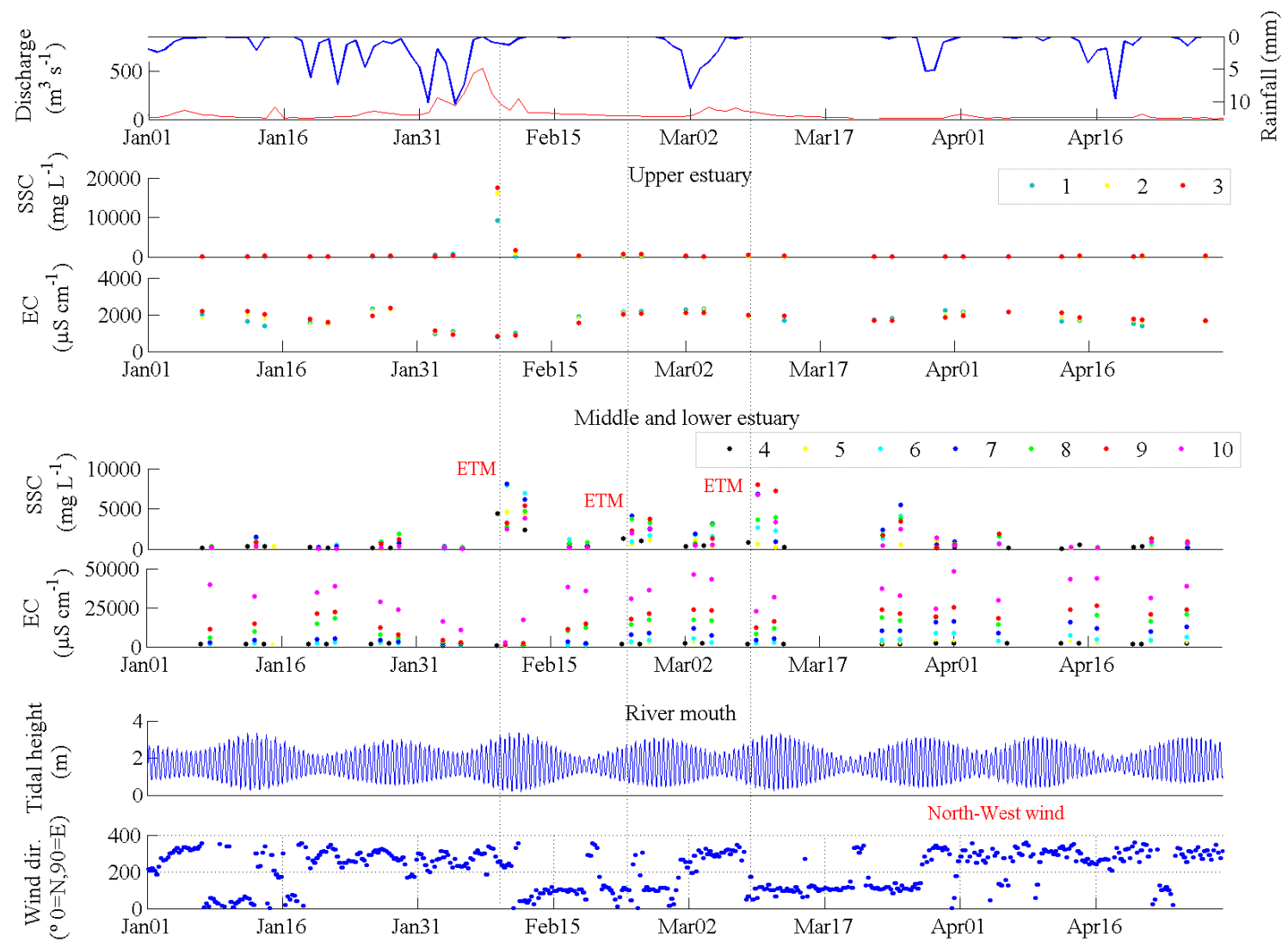

Fig. 5. Mean daily rainfall in the basin upstream of the estuary, daily discharge from the Alcalá del Río dam, SSC and EC in the upper, middle and lower estuary, tidal height and wind direction in the river mouth, period January-April 2009.

and comparing data at a monthly and weekly scale with data proceeding from automatic networks is useful to scientists and public authorities, who can be oriented towards choosing an adequate sampling frequency and spatial extent so as to carry out the monitoring (with optimized costs) according to the variable of interest.

These requirements could be necessary in estuaries where the SSC can reach more than $1000 \mathrm{mg} \mathrm{L}^{-1}$, such as the Hudson (Geyer at al., 2001) and Ashapoo (Milligan et al., 2001) estuaries in USA, Chang Jiang estuary (Shi, 2002) in China and Tamar (Grabemann et al., 1997) and Humber (Uncles et al., 2006) estuaries in the UK, in order to detect great loads of sediments in the head of the estuary and predict the turbidity generated in the middle and lower stretches. Also, it could be an important control requirement in estuaries where extremely high SSC is detected in their contributing areas, as is the case of the Guadalquivir estuary, where there are agricultural soils with high loss rates, especially in cropping systems such as olive orchards and herbaceous crops (Contreras and Polo, 2011). This is especially useful in areas with a Mediterranean type climatology, in which periods of drought alternate with rain events of a great intensity in a short period of time.

\section{Conclusions}

The influence of the temporal scale on the analysis of water quality data from different sources differs according to the variable under study. For turbidity in the Guadalquivir estuary, data are required at least at a weekly scale along the whole estuary, while for salinity (smooth variations as average), this scale is required only in the lower estuary, where the tide has more influence (in the upper estuary, the monthly scale data could be enough).

In order to capture extreme turbidity episodes, the sampling rate may be decreased in the lower estuary, while upstream higher frequency is required to determine the characteristic time scales and forcing agents of turbidity. In these complex aquatic systems, the spatial scale of sampling is important for characterizing the water quality in each individual stretch, whose geomorphology, together with its forcing agents, determines the variability in the different water quality variables. This will have a positive feedback for the implementation of monitoring networks in estuaries, pointing the way to local authorities, which should create the desirable management framework and facilities for the Guadalquivir estuarine ecosystem conservation in order to preserve its multifunctional nature. In the future, integrated solutions 
should consider regional and national networks for estuarine ecosystem monitoring for the reasons pointed out above.

The results of this work can be applied in estuaries with similar characteristics to the Guadalquivir estuary, which presents a strong but transient fluvial dominance in the upper estuary and a quasi-permanent tidal dominance in the lower estuary, affected by large loads of sediments from the contributing areas (which is especially Mediterranean agricultural areas) associated with a marked intra-annual and seasonal variability related to rainfall events.

Acknowledgements. The results of this work have been obtained within the framework of cooperation agreements between the Spanish National Research Council (CSIC) and the Universities of Granada and Cordoba, entitled: "Proposed methodology for diagnosing and predicting the consequences of human actions in the Guadalquivir estuary" and the excellent project of the Andalusian Regional Government RNM-4735 "Dynamic of suspended solids in estuarine waters“. The authors would like to thank the Andalusian Regional Government and the Spanish Ports Authority for providing water quality data, and the reviewers for their valuable comments and suggestions which have greatly improved this paper.

Edited by: J. A. Santos

Reviewed by: J. C. Lima and two other anonymous referees

\section{References}

Álvarez, O., Tejedor, B., and Vidal, J.: Tidal dynamic in the Guadalquivir estuary: a peculiar case of anthropic resonance, Earth Phys., 13, 11-24, 2001.

Baker, E. T. and Lavelle, J. W.: The effect of particle size on the light attenuation coefficient of natural suspensions. J. Geophys. Res., 89, 8197-8203, 1984.

Bramato, S., Contreras, E., Polo, M. J., and Losada, M. A.: An integrated database manager to forecast estuarine dynamics and water quality in the Guadalquivir river (Spain), River Flow 2010, 2, 1415-1420, 2010.

Bustamante, J., Pacios, F., Díaz-Delgado, R., and Aragonés, D.: Predictive models of turbidity and water depth in the Donana marshes using Landsat TM and ETM+ images, J. Enviro Manage., 90, 2219-2225, 2009.

Contreras, E. and Polo, M. J.: Propuesta metodológica para diagnosticar y pronosticar las consecuencias de las actuaciones humanas en el estuario del Guadalquivir (in Spanish), technical report, Group of Fluvial Dyn. and Hydrol., Univ. of Córdoba, Córdoba, Spain, 2010.

Contreras, E. and Polo, M. J.: Influence of reservoirs and land use changes on the river contribution: case study of the Guadalquivir estuary, Geophys. Res. Abstr., 13, 12719, 2011.

Díez-Minguito, M., Bramato, S., Contreras, E., Polo, M. J., and Losada, M. A.: Distribución espacial de salinidad y turbidez en estuario del Guadalquivir, XI Jornadas Españolas de Costas y Puertos, Las Palmas de Gran Canaria, Spain, 2011.
Dyer, K. R.: Estuaries: A physical Introduction. 2nd ed., John Wiley \& Sons, Chichester, UK, 195 pp., 1997.

Etcheber, H., Schmidt, S., Sottolichio, A., Maneux, E., Chabaux, G., Escalier, J.-M., Wennekes, H., Derriennic, H., Schmeltz, M., Quéméner, L., Repecaud, M., Woerther, P., and Castaing, P.: Monitoring water quality in estuarine environments: lessons from the MAGEST monitoring program in the Gironde fluvial-estuarine system, Hydrol. Earth Syst. Sci., 15, 831-840, doi:10.5194/hess-15-831-2011, 2011.

Geyer, W., Signell, R., and Kineke, G.: Lateral trapping of sediment in a partially mixed estuary, in: Physics of Estuaries and Coastal Seas, edited by: Dronkers, J. and Sheffers, A. A., Balkema, Rotterdam, 115-124, 1998.

Geyer, W., Woodruff, J., and Taraykovski, P.: Sediment transport and trapping in the Hudson River Estuary, Estuaries, 24, 670679, 2001.

González-Ortegón, E., Subida, M. D., Cuesta, J. A., Arias, A. M., Fernández-Delgado, C., and Drake, P.: The impact of extreme turbidity events on the nursery function of a temperate European estuary with regulated freshwater inflow, Estuar. Coast Shelf S., 87, 311-324, 2010.

Grabemann, I., Kappenberg, J., and Krause, G.: Aperiodic variations of the turbidity maxima of two German coastal plain estuaries, Neth. J. Aquat. Ecol., 29, 217-227, 1995.

Grabemann, I., Uncles, R. J., Krausec, G., and Stephens, J. A.: Behaviour of Turbidity Maxima in the Tamar (U.K.) and Weser (F.R.G.) Estuaries. Estuar. Coast Shelf S., 45, 235-246, 1997.

Hardisty, J.: Estuaries, Monitoring and modeling the physical system, Blackwell, Singapore, 157 pp., 2007.

Herrero, J., Aguilar, C., Polo, M. J., and Losada, M. A.: Mapping of meteorological variables for runoff generation forecast in distributed hydrological modeling, Hydraulic measurements and Experimental Methods, New York, 606-611, 2007.

López-López, J. A., García-Vargas, M., and Moreno, C.: A chemometric approach to the evaluation of atmospheric and fluvial pollutant inputs in aquatic systems: The Guadalquivir River estuary as a case study, Environ. Pollut., 159, 1136-1143, 2011.

Mendiguchía, C., Moreno, C., and García-Vargas, M.: Evaluation of natural anthropogenic influences on the Guadalquivir River (Spain) by dissolved heavy metals and nutrients, Chemosphere, 69, 1509-1517, 2007.

Milligan, T. G., Kineke, G. C., Blake, A. C., Alexander, C. R., and Hill, P. S.: Flocculation and sedimentation in the ACE basin, South Carolina, Estuaries, 24, 5, 734-744, 2001.

Navarro, G., Gutiérrez, F., and Díez-Minguito, M.: Temporal and spatial variability in the Guadalquivir estuary: a challenge for real time telemetry, Ocean Dynam., 61, 753-765, 2011.

Pritchard, D. W.: Estuarine hydrography, Adv. Geophys., 1, 243280, 1952.

Sanford, L., Suttles, S., and Halka, J.: Reconsidering the Physics of the Chesapeake Bay Estuarine Turbidity Maximum, Estuaries, 24, 655-669, 2001.

Shi, Z.: Dynamics of the turbidity maximum in the Changjiang Estuary, China, Proceed. Marine Sci., 5, 655-669, 2002.

Uncles, R. J., Stephens, J. A., and Law, D. J.: Turbidity maximum in the macrotidal, highly turbid Humber Estuary, UK: Flocs, fluid mud, stationary suspensions and tidal bores, Estuar. Coast Shelf S., 67, 30-52, 2006. 